\title{
PENTINGNYA AKREDITAS RUMAH SAKIT DALAM MELAKUKAN PROSES KESELAMATAN PASIEN
}

\author{
Angel Ester Simanjuntak / 181101142 \\ angelester85@gmail.com
}

\begin{abstract}
ABSTRAK
Latar belakang: Pasal 40 ayat (1) UU nomor 44 tahun 2009 juga menyebut bahwa dalam upaya meningkatkan mutu pelayanan rumah sakit wajib dilakukan akreditasi secara berkala minimal tiga tahun sekali. (Kemenkes, 2009). Tujuan: untuk mengetahui bahwa pentingnya akreditas rumah sakit pada peberian pelayanan kepada pasien. Metode: analisis data sekunder Hasil: Menurut Jurnal Ilmiah Universitas Batanghari Jambi, yang berjudul Gaya Kepemimpinan dan Komitmen Paramedis dalam Implementasi Akreditasi Rumah Sakit Versi SNARS, menyatakan bahwa Gaya kepemimpinan dan komitmen paramedis dalam implementasi akreditasi rumah sakit menunjukkan hubungan yang kuat dan berpola positif. Artinya semakin baik gaya kepemimpinan yang dipraktikan semakin baik komitmen paramedis yang terbentuk.Pembahasan: Akreditasi rumah sakit adalah suatu pengakuan dari pemerintah atau komite akreditasi nasional Komite Akreditasi Rumah Sakit (KARS) Indonesian dan Comission on Acreditation of Hospital and Other Health (ICAHO) kepada rumah sakit dan sarana kesehatan lainnya yang telah memenuhi standar yang telah ditetapkan. Penutup: akreditas merupakan salah satu dampak dalam pemberian pelayanan yang baik, dan dengan adanya gaya kemepemimpinan yang baik akan membuat karyawan akan siap dalam berpartisipasi dalam proses implementasi akreditas rumah sakit yang baik.
\end{abstract}

Kata Kunci : akreditasi, gaya kepemimpinan, keselamatan pasien 


\section{LATAR BELAKANG}

semakin berkembangnya ilmu dan teknologi pelayanan kesehatan khususnya di rumah sakit menjadi kompleks dan berpotensi terjadinya Kejadian Tidak Diharapkan apabila tidak dilakukan dengan hati-hati. Kementerian kesehatan menyatakan bahwa akreditasi merupakan langkah untuk menjamin rumah sakit agar mengutamakan pelayanan, keselamatan dan perlindungan masyarakat, sehingga akreditasi wajib bagi pelayanan kesehatan.

Rumah sakit mempunyai banyak potensi bahaya yang dapat mengancam jiwa dan kehidupan khususnya untuk karyawan di rumah sakit, para pasien dan para pengunjung yang ada di lingkungan rumah sakit (Kemenkes, 2007).

International Labour Organization (ILO) menyatakan bahwa, 2,78 juta pekerja di seluruh dunia meninggal setiap tahun karena kecelakaan pada saat bekerja dan penyakit akibat kerja. Sekitar 86,3\% yang mengakibatkan kematian bagi pekerja yaitu penyakit akibat kerja. Sementara lebih dari 13,7\% terjadi karena kecelakaan kerja fatal.

Undang-Undang Nomor 44 Tahun 2009 Tentang Rumah Sakit, Pasal 29 huruf b menjelaskan bahwa rumah sakit wajib memberikan pelayanan kesehatan yang aman, bermutu, anti diskriminasi dan efektif dengan mengutamakan kepentingan pasien sesuai dengan standar pelayanan rumah sakit. Pasal 40 ayat (1) UU nomor 44 tahun 2009 juga menyebut bahwa dalam upaya meningkatkan mutu pelayanan rumah sakit wajib dilakukan akreditasi secara berkala minimal tiga tahun sekali. (Kemenkes, 2009). Dari undang undang tersebut, akreditasi rumah sakit penting untuk dilakukan dengan alasan agar mutu dan kualitas diintegrasikan dan dibudayakan ke dalam sistem pelayanan di rumah sakit ditambah lagi BPJS mensyaratkan bekerjasama dengan rumah sakit yang sudah terakreditasi.

Sebagai salah satu subsistem dalam pelayanan kesehatan rumah sakit menjadi tempat rujukan bagi unit-unit pelayanan kesehatan dasar. Rumah sakit adalah suatu bentuk organisasi yang bergerak dalam bidang jasa, pelayanan dengan ciri-ciri padat karya, padat modal, padat teknologi, padat masalah dan padat urnpatan, kegiatan akreditasi rnerupakan bentuk perhatian dan perlindungan pemerintah dengan mernberikan pelayanan yang profesional.

Melakukan tindakan yang sesuai dengan prosedur salah satu tindakan yang dianggap ringan namun sering dilupakan adalah mencuci tangan. Ketika akan melakukan suatu pekerjaan mencuci 
tangan sendriri adalah bagian dari pencegahan dan pengendalian infeksi dan salah satu indikator kualitas layanan rumah sakit. Kualitas layanan rumah sakit sangat terkait dengan kepuasan pasien, sebagai penerima layanan kesehatan. Akan tetapi, tindakan mencuci tangan sebelum dan sesudah tindakan masih jarang dilakukan karena kurangnya kesadaran dari diri petugas kesehatan khususnyaa perawat itu sendiri.

\section{TUJUAN}

Kajiian ini bertujuan untuk mengetahui bahwa pentingnya akreditas rumah sakit pada peberian pelayanan kepada pasien.

\section{METODE}

Metode yang digunakan dalam kajian menggunakan analisis data sekunder yang dimana kajian bersumber dari jurnal dan buku.

\section{HASIL}

Menurut Jurnal Ilmiah Universitas Batanghari Jambi, yang berjudul Gaya Kepemimpinan dan Komitmen Paramedis dalam Implementasi Akreditasi Rumah Sakit Versi SNARS, menyatakan bahwa Gaya kepemimpinan dan komitmen paramedis dalam implementasi akreditasi rumah sakit menunjukkan hubungan yang kuat dan berpola positif. Artinya semakin baik gaya kepemimpinan yang dipraktikan semakin baik komitmen paramedis yang terbentuk. Dalam penelitian ini ditemukan bahwa atasan langsung paramedis berusaha menerapkan berbagai gaya kempeimpinan dalam praktik kepemimpinannya untuk menguatkan komitmen paramedis dalam implementasi akreditasi dengan karakteristik paramedis berlatar belakang pindidikan D3 dan masa kerja kurang dari 5 tahun. Hasil penelitian menyimpulkan bahwa gaya kepemimpinan orientasi prestasi adalah gaya kepemimpinan yang dianggap paling mampu membangun komitmen paramedis dalam implementasi akreditasi.

\section{PEMBAHASAN}

Akreditasi rumah sakit adalah suatu pengakuan dari pemerintah atau komite akreditasi nasional Komite Akreditasi Rumah Sakit (KARS) Indonesian dan Comission on Acreditation of Hospital and Other Health (ICAHO) kepada rumah sakit dan sarana kesehatan lainnya yang telah memenuhi standar yang telah ditetapkan.

$$
\text { Akreditasi dapat mendorong }
$$
perawat supaya lebih memperhatikan upaya keselamatan pasien di rumah sakit, diantaranya penerapan standar opeasional prosedur yang lebih baik dalam upaya pencegahan infeksi, mobilisasi pasien, dan asuhan keperawatan.

Gaya Kepemimpinan merupakan suatu cara yang dimiliki oleh seseorang 
dalam mempengaruhi sekelompok orang atau bawahan untuk bekerja sama dan berdaya upaya dengan penuh semangat dan keyakinan untuk mencapai tujuan yang telah ditetapkan. Keberhasilan suatu organisasi baik sebagai keseluruhan maupun berbagai kelompok dalam suatu organisasi tertentu, sangat tergantung pada efektivitas kepemimpinan yang terdapat dalam organisasi yang bersangkutan. Dapat dikatakan bahwa mutu kepemimpinan yang terdapat dalam suatu organisasi memainkan peranan yang sangat dominan dalam keberhasilan organisasi tersebut dalam menyelenggarakan berbagai kegiatannya.

Gaya kepemimpinan orientasi prestasi dalam penelitian ini mampu meningkatkan komitmen paramedis dalam implementasi akreditasi rumah sakit. Hal ini karena paramedis merasa bahwa apa yang dikerjakan berharga, paramedis merasa nyaman bekerja, paramedis merasa mendapat dukungan penuh dari pimpiman dan manajemen berupa misi dan nilai-nilai yang jelas yang berlaku di rumah Sakit.

seorang karyawan yang memiliki persepsi bahwa akreditasi akan membawa manfaat bagi perkembangan rumah sakit tempat dia bekerja, maka akan meningkatkan keinginan karyawan tersebut untuk berpartisipasi dalam proses persiapan akreditasi. Hasil penelitian ini konsisten dengan penelitian yang dilakukan oleh Wantouw et al., (2014) yang menunjukkan bahwa persepsi berpengaruh positif pada partisipasi.

Rasa bergairah terhadap pekerjaan paramedis di rumah sakit timbul karena pimpinan memberi perhatian pada hasil kerja paramedis, pimpinan memberi delegasi wewenang kepada paramedis dalam implementasi akreditasi, serta memberi kesempatan serta ruang yang cukup bagi paramedis untuk menggunakan keterampilan dan keahliannya secara maksimal. Pimpinan rumah sakit juga melibatkan paramedis dalam membuat keputusankeputusan yang berhubungan dengan implementasi akreditasi rumah sakit.

\section{PENUTUP}

Dari kajian ini dapat disimpulkan bahwa akreditas merupakan salah satu dampak dalam pemberian pelayanan yang baik, dan dengan adanya gaya kemepemimpinan yang baik akan membuat karyawan akan siap dalam berpartisipasi dalam proses implementasi akreditas rumah sakit yang baik.

\section{REFERENSI}

Dewi, N. P. (2019). Analisis Pelaporan Insiden Keselamatan Pasien Kasus Obstetri Dan Ginekologi Di Salah Satu Rumah Sakit Umum Swasta Di 
Yogyakarta (Doctoral dissertation,

Universitas' Aisyiyah Yogyakarta).

Donny, Z. Z. (2019). Tata Kelola Rumah

Sakit Melalui Akreditasi (Snars 2018)

Dalam Penerapan Good Corporate

Governance (Studi Kasus Di Rs. Tamar

Medical Centre-PARIAMAN) (Doctoral

dissertation, Universitas Andalas).

Ginting, d. (2019). Gaya Kepemimpinan

dan Komitmen Paramedis dalam

Implementasi Akreditasi Rumah Sakit

Versi SNARS. Jurnal Ilmiah Universitas

Batanghari Jambi , 504-508.

Kemenkes RI. UU No 44 Tahun 2009

Tentang Rumah Sakit. Jakarta: Kemenkes RI

Kemenkes RI. PERMENKES RI NO.

12/MENKES/PER/IV/2012 Tentang

Akred

Nugraha, H. S. Hubungan Penerapan Cuci

Tangan Dengan Kepuasan Pasien Diruang

Rawat Inap Rumah Sakit Anton Soedjarwo

Pontianak. Jurnal ProNers, 4(1).

Punuh, d. (2019). ANALISIS

\section{PELAKSANAAN PROGRAM}

KESEHATAN DAN KESELAMATAN.

Jurnal KESMAS, Vol. 8, No. 5 .

Potter, P. A \& Perry, A. G. (2005). Buku Ajar

Fundamental Keperawatan: Konsep, Proses

Dan Praktik. Edisi 4. (Y. Asih et al,

penerjemah). Jakarta: EGC.
Salawati, L., Taufik, H. N., Putra, A. (2014).

Analisis Tindakan Keselamatan Dan Kesehatan

Kerja Perawat Dalam Pengendalian Infeksi

Nosokomial Di Ruang ICU RSUD dr. Zainoel

Abidin Banda Aceh. Volume 14, Nomor 3.

Simamora, R.H. (2019). Buku Ajar :

Pelaksanaan Identifikasi Pasien.

Ponorogo, Jawa Timur: Uwais Inspirasi

Indonesia.

Simamora, R.H. (2019). The Influence Of

Training Hand Over Based SBAR Communication For Improving Patients

Safety. Indian Journal OfPublic Health Research \& Development

Widyaningrum, L. (2013). PENGARUH

PRE AKREDITASI JCI (JOINT COMMISSION INTERNATIONAL)

TERHADAP KELENGKAPAN DATA

REKAP MEDIS RESUME PASIEN

RAWAT INAP RUMAH SAKIT Dr. MOEWARDI SURAKARTA. Jurnal Ilmiah Rekam Medis dan Informatika Kesehatan, INFOKES, VOL. 3 NO. 3 .

Widiyanti. Pengaruh Gaya Kepemimpinan Prestasi Terhadap Kinerja Dengan Varibel Moderasi Partisipasi Pengambilan Keputusan dan Need for achiement. Jurnal ekonomi dan kewirausahaan Vol 12, No 2, Oktober 2012: 124-131.2012. 
Yulistian A.S. (2011). Pengaruh Gaya

Kepemimpinan Direktif, Suportif, Dan

Orientasi Prestasi Terhadap Semangat

Kerja Karyawan (Studi Pada Karyawan

Bank Rakyat Indonesia Cabang

Lamongan). Naskah publikasi. Malang:

Universitas Brawijaya 